\title{
LA PRESENCIA DEL DIÁLOGO EN \&LA CITA" DE JOSÉ MARÍA EGUREN
}

Resumen: El quehacer literario de José María Eguren (Lima, 1874-1942) en el siglo XX permitió una renovación moderna en el estilo de la poesía peruana. Uno de los rasgos literarios de la producción artística del afamado poeta constituye la presencia del diálogo, categoría que lo utiliza estratégicamente

* Williams Nicks Ventura Vásquez es magíster en Literatura Peruana y Latinoamericana y licenciado en Literatura por la Universidad Nacional Mayor de San Marcos. Su interés en el campo de investigación se enfoca en la poesía, la narrativa y, sobre todo, en evaluar el valor poético de las piezas dramáticas de los escritores más representativos de la literatura peruana de siglo XX. Ha participado en diversos congresos literarios organizados por la Academia Peruana de la Lengua, la Casa de la Literatura Peruana, el CELACP, entre otros; $y$ ha publicado en diferentes revistas. Actualmente, se desempeńa como corrector de estilo y ejerce la docencia universitaria en la UCSS y la UPN. 
a modo de recurso poético y que lo acerca a los parámetros del discurso teatral. Por ello, mediante las propuestas teóricas de la Retórica General Textual (Stefano Arduini) y la Semiología del texto dramático (Bobes Naves), la presente investigación pretende dilucidar el manejo de la mencionada herramienta estética en un caso particular, "La cita" poema perteneciente a Rondinelas.

Palabras clave: Poesía peruana, Eguren, "La cita", diálogo.

\title{
THE PRESENCE OF DIALOGUE IN \&LA CITAP OF JOSÉ MARÍA EGUREN
}

\begin{abstract}
The literary work of José María Eguren (Lima, 1874-1942) in the 20th century allowed a modern renovation in the Peruvian poetry style. One of the literary features of this famous poet's artistic production is the presence of dialogue, category that uses it strategically as a poetic resource and that brings it closer to the theatrical discourse parameters. Therefore, following the theoretical proposals of the General textual rhetoric (Stefano Arduini) and the dramatic text semiology (Bobes Naves), the present research aims to elucidate the management of the aforementioned aesthetic tool in a particular case, "La cita" belonging poem to Rondinelas.
\end{abstract}

Keywords: Peruvian poetry, Eguren, "La cita”, dialogue.

\section{Eguren, un Poeta de Renovación Estilística}

Tosé María Eguren es considerado por su producción lírica como el fundador de la poesía moderna de la literatura peruana. Simbólicas (1911) y La canción de las figuras (1916) inquietaron sobremanera el quehacer poético cuando empezaba la fase final de la tendencia estética modernista. El insólito manejo de la sugerencia del símbolo y la destreza estructural y musical del verso, conllevaron a determinar que se trataba de una expresión compleja. Ante ello, las indagaciones de la crítica especializada han reivindicado, evaluado y expuesto la labor literaria de tan reconocido poeta. 
En Equivocaciones (1928), Jorge Basadre resalta en Eguren el intrépido desprendimiento de una poesía asequible a la comprensión del público. Esto con la finalidad de consagrarse con una creación afín a sus propósitos juicios estéticos. Dichas composiciones, según Basadre, pretenden acercarse a los efectos de una autónoma literatura artística, aunque cause la desaprobación y "el malestar de la incomprensión" del lector (p. 15).

En La imaginación crítica (1974), Julio Ortega considera que los poemas de Eguren exhiben un idealismo poético a través de símbolos, una conciencia del diseño rítmico, una tendencia lúdica de la vida y la muerte, y un juego secreto de las formas mínimas. Un aspecto elemental de los versos egurenianos constituye la mirada antitética que desemboca a la visión irreal y el fomento de lo ambiguo. Esta "escisión", señala Ortega, demuestra la mirada desconcertante e inusual ante el misterio, lo desconocido y la muerte (p. 23).

Enrique Peña Barrenechea, en "Aspectos de la poesía de Eguren" (1977), reconoce que los lineamientos formativos de Eguren provienen de un "tono romántico" con una "contención verbal, no del sentimiento" que lo conlleva a una "recatada confidencia sentimental" (p. 111). Dicha tonalidad romántica coexiste de manera armónica con la presencia de la sugestión, el color y la música, aspectos del simbolismo. Un ejemplo interesante, aunque sin la debida exploración, resulta la comparación que realiza con el teatro de Maurice Maeterlinck: indica que las destrezas dramáticas constituidas en el escenario, "la visibilidad de lo invisible, el universo de la infancia, los reflejos del bosque" del dramaturgo belga (p. 115) se observan en los paisajes nocturnos y las fantasmales presencias de la lírica egureniana ${ }^{1}$.

Washington Delgado, en Historia de la literatura peruana (1984), coloca a la poesía de Eguren en un marco de la perfección última del modernismo peruano. La extrema originalidad que determinó su difícil comprensión, indica Delgado, termina por liberarse de

Considerando que el interés principal de Eguren fue comprender el Arte en sus diversas expresiones, además de su encanto por la pintura y la música, en ciertas entrevistas señala una predilección por autores dramáticos de la época como Maurice Maeterlinck y Gabriel D’Anunnzio. En la Prosa completa (2015b), en una correspondencia dirigida a Pedro Zulen, en 1917, señala que conserva los libros de Maeterlinck (p. 224); y, en una entrevista publicada en Variedades en 1922, indica que uno de sus libros preferidos fue Las virgenes de las rocas de D’Annunzio (p. 312). 
las contorsiones extravagantes de versos artificiosos hacia una "música íntima y asordinada, mediante versos breves y rimas asonantes" (p. 108). Estos elementos le permiten al crítico anunciar una nueva sensibilidad lírica, una etapa próxima al vanguardismo peruano.

Por último, James Higgins (2006) establece que los elementos simbolistas de la producción lírica de Eguren exigen al lector a adoptar una actitud activa solo si pretende desentrañar el verdadero significado del universo imaginativo. Para Higgins, "una anécdota o viñeta dramática (...) suelen estar ambientados en marcos remotos que lo alejan de la realidad cotidiana" (p. 121).

\section{Aproximaciones a "La cita", Poema Perteneciente a Rondinelas}

Z n 1929, José Carlos Mariátegui editó Poesías, en donde se volvieron a publicar los - primeros poemarios de Eguren con la incorporación de algunos poemas de Sombra y Rondinelas. Sobre esta última colección, para Julio Ortega (1974), se evidencia la destreza técnica, la depuración rítmica y el sentimiento de la armonía interior. El interés del poeta ya no consiste en perseguir la imagen del misterio, sino en desenvolverse en esa fantasía: Eguren sugiere "en su mismo hermetismo aquella indeterminación" de lo real (p. 41).

Por su parte, Ricardo Silva-Santisteban, en El universo poético de José María Eguren (2016), considera que si Simbólicas establece el inicio de la poesía peruana contemporánea, Rondinelas responde a un estilo de madurez que no rompe de manera categórica con su tendencia poética. En este poemario, según el crítico, el "refinamiento verbal” egureniano evidencia un tono y contenido refinado y sencillo debido a la "austeridad" de las enunciaciones y al empleo de procedimientos estilísticos, los cuales le permiten expresar lo íntimo y lo misterioso. Asimismo, la presencia de un "hermetismo cerrado" le permite a Eguren impartir una instrumentación de símbolos y elementos retóricos que progresivamente despliegan diversas interpretaciones.

Dentro del repertorio de Rondinelas vamos a concentrarnos en "La cita". Originariamente este poema no apareció en Poesías publicado por el Amauta. Según la edición de Poesías completas (2015a), el discurso lírico a tratar se coloca en el manuscrito de Rondinelas en el vigésimo segundo lugar de un total de treinta composiciones. Asimismo, llegó a publicarse por primera vez en la revista Social N 267 en mayo de 1942. Sobre "La cita", a diferencia de sus poemas más emblemáticos como "Lied I", "La walkyria”, "Los reyes rojos", "El duque" o "La niña de la lámpara azul", no ha tenido una cantidad notable de 
estudios críticos. Por ello, solo hemos encontrado dos acercamientos desde un eje temático y rítmico-semántico.

Según Elguera (2014), el poema revela el tópico “vannitas” al exponerse la trágica permanencia del hombre frente a la muerte. Indica que al iniciar la lectura la figura tétrica no provoca incomodidad ni contiene una carga siniestra, sino que el carácter estético la familiariza con la belleza. Sin embargo, esta imagen de beldad se va diluyendo progresivamente hasta desvelar el verdadero perfil de lo mortuorio, lo peligroso y lo sobrenatural. De esa manera, se expone la fragilidad y el fracaso del hombre por pretender eludir el llamado de la muerte.

Por otro lado, Lino Salvador (2017) demuestra que el poema contiene una simetría de intensidad de tiempos marcados que se complementan con una flexibilidad rítmica, lo cual enriquece el contenido semántico. Para Lino, el manejo de las estrofas pareadas posibilita el intercambio de informaciones entre los personajes. Además, sugiere que el poema, a partir de los campos figurativos de la metáfora y la antítesis, crea un ambiente matizado por la eterna oscuridad y el conflicto del sujeto al enfrentarse contra la muerte.

Creemos que estas revisiones se centran acertadamente en la revisión de los tópicos más frecuentes y en la innegable conciencia rítmica de Eguren. Por nuestra parte, queremos aportar con un análisis en un elemento discursivo estratégico dejado de lado, pero notoriamente visible: la presencia del diálogo en la organización sistemática del poema.

\section{El Diálogo en "La cita"}

Tn rasgo que determina "La cita" es la percepción del diálogo. Esta categoría frecuentemente usada en los textos narrativos y dramáticos condiciona la lectura del poema ${ }^{2}$. De acuerdo con los criterios desarrollados por Bobes Naves (2009), el "diálogo" remite a una forma concreta del intercambio lingüístico; es decir, la fijación directa del fenómeno interactivo de la comunicación provisto de un valor y código social entre el emisor y el receptor.

La teórica indica que el criterio comunicativo del diálogo es recurrente en todos los géneros literarios y sobresale dependiendo de las pretensiones del autor.

Debemos indicar que este poema no es el único con rasgos de una interacción dialógica. En un rastreo de los textos poéticos encontramos veinte poemas con la misma tendencia. De Simbólicas: "Ananké", "Nora", "Juan Volatín"; de La canción de las figuras: "Noche II", "El horóscopo de las infantas", "Canción frívola”, "Lied VI", "Negro sayón"; de Sombras: "Visiones de enero"; de Rondinelas, aparte del texto a analizar: "Nocturno"; y, de la sección poemas no recogidos en libros: "Campestre". 
Podemos decir, entonces, que si en un discurso dramático el diálogo constituye un elemento vital para la construcción expresiva de los personajes en plena ficción teatral, esta intención locutiva también puede aparecer dentro de la estructura de un poema sin disminuir la intensidad lírica. El poeta puede utilizar la forma libre del diálogo y colocarlo como una alternativa literaria que le permite acondicionar las intervenciones de los interlocutores.

Si bien se establece de modo general que el discurso lírico contiene la voz del yo poético, respondiendo a la expresión subjetiva, en ocasiones el discurso incorpora ciertos recursos dramáticos de la construcción lírica. Esta creación literaria, con una intensidad semiótica, puede llegar a ser considerado un género lírico-dramático, una organización híbrida de lo lírico y lo dramático³.

Para empezar con nuestro análisis, transcribimos el poema en su totalidad:

Venturón bonancible protesta que lo llamen mitad de la fiesta.

- Monseñor, han tocado la puerta y lo está esperando una muerta.

- Hora danzo entre brillos y lacas y me hastían las gentes opacas.

- Monseñor, si semeja una rosa que murmura gentil, misteriosa.

3 No podemos omitir la interesante propuesta de Amaia Rieco (1998) al determinar el carácter dramático del diálogo y el monólogo, susceptibles a la puesta en escena, en los "poemas duologados" de Rafael Alberti. Según Rieco, los poemas constituyen un discurso híbrido entre la lírica y el drama a partir de componentes de la dicción y la enunciación, estrategias comunicativas que indican movimientos escénicos por parte de interlocutores distintos de la voz del "yo poético". Este tipo de poema, cuyos antecedentes hispánicos pueden visualizarse en las jarchas, las églogas, las letrillas dialogadas, etc., "es un género adscrito a la lírica pero que, sin embargo, ha buscado dramatizar la liricidad a través de mecanismos expresivos de los que se ha servido habitualmente el drama como el diálogo y el monólogo dramáticos, la división en escenas, los interlocutores ficticios, etc." (p. 91). 
Es tal vez una sombra preclara,

Señorón; y ¡qué cara!, ¡qué cara!...

$-\succsim$ Es acaso la luna sin vida?

- Una cańa del viento florida.

$-¿ Y$ sus ojos son negros y hondos?

- Se diría dos mundos redondos.

No son galos, ni son zahareños,

son la noche de todos los sueños.

Con su talle de avispa provoca

la elegancia, y su boca jsu boca!...

Cuenta lindo paisajes dormidos, cuenta cielos del alma floridos.

Quiere hablarte con voz de salterio, - ¿Qué dirá? ¿Qué anhela?... ¡un misterio!

- Corazón desvelado e inerte,

hoy te cita de amores la Muerte.

Desde un enfoque rítmico, "La cita" expone una estructura determinada por doce pares de versos decasílabos con una rima consonántica en cada estrofa. En esta expresión poética, las indicaciones semánticas señalan un movimiento progresivo del argumento sobre una organización dialogada. Verbigracia: en medio de una fiesta, un emisario comunica al Monseñor que una dama lo solicita; después de una breve charla, se revela que se trata de la Muerte.

Debemos tener presente que toda forma dialogada no proporciona necesariamente una marca dramática, pero tampoco debemos obviar que el discurso 
lírico prescinde de dicha dramaticidad al incorporarse este recurso literario ${ }^{4}$. Por tanto, para una mejor comprensión del poema, partiremos de las características más resaltantes de la esencia dramática, debido a la presencia del diálogo, mencionadas por Bobes Naves (1997), quien indica que "los enfrentamientos verbales, expresados con exuberancia y sometidos a las medidas de sílabas y a la rima, no impiden que la interacción verbal, por turnos, cara a cara, segmentada, sean claros y radicales, es decir, sean diálogos" (p. 266). Asimismo, resaltaremos los campos figurativos propuestos por Stefano Arduini (2000) con la finalidad de evidenciar las "estructuras universales de organización expresiva del pensamiento” (p. 136) de Eguren.

\subsection{La aparición del narrador-poeta}

$\mathrm{Al}$ inicio se evidencia la creación textual mediante una voz poética perteneciente a un locutor personaje dirigiéndose a un alocutario no representado. La enunciación, a modo de un espectador lejano, describe una acción en un ambiente determinado:

\section{Venturón bonancible protesta}

que lo llamen mitad de la fiesta.

En este fragmento, el efecto comunicativo se diseńa con la presencia de un enunciador que va a desaparecer para dar paso a una secuencia comunicativa sin obviar el régimen de la forma interna del verso. Reconocemos, entonces, la aparición del narradorpoeta que registra el fastidio de "Venturón bonancible" en medio de una festividad. Desde el campo figurativo de la metáfora, evidenciamos que la referencia temporal de la "mitad" de la ceremonia nos sugiere que en la cúspide de la vida del Monseñor, llena de algarabía y prosperidad, se ve interrumpida por una visita insospechada.

Distinguimos en el poema un diálogo artístico por la calidad estética del lenguaje y la condensación sintética del contenido. Conforme a Isabel Paraíso (1976), esta modalidad del diálogo "lo hace en general dentro de los límites de la más ortodoxa gramática, y con una concisión y un ingenio que raramente se dan en la realidad" (p. 262). 


\subsection{El diálogo textualizado}

La intensidad dramática del poema se refuerza con la percepción del diálogo textualizado. Las concordancias gramaticales e intervenciones lógicas, acentuado con el signo paralingüístico del guion, presuponen la alternancia de dos enunciaciones. Una vez que el narrador-poeta presenta el espacio de acción y menciona la circunstancia, se alternan una serie de intervenciones dialectales 5 .

De esta manera, el lector siente la mecánica del diálogo: la secuencia de intervenciones coherentes empieza cuando el emisario enuncia la presencia de una muerta a "Venturón bonancible". Esta repentina intervención conlleva a que el Monseñor se indigne en medio del jolgorio.

- Monseñor, han tocado la puerta

y lo está esperando una muerta.

- Hora danzo entre brillos y lacas

y me hastían las gentes opacas.

La referencia del emisario sobre una desconocida "muerta" que espera en la puerta no causa interés o estremecimiento en el Monseñor, mas bien la inesperada solicitud lo incomoda, le parece indecoroso reunirse con un ser inferior en vez de seguir en compañía de distinguidas personas.

Desde un enfoque antitético, se percibe una tensión de las oposiciones de la luminosidad (lo opaco con el brillo y la laca), el movimiento (la espera con la danza) y los individuos (la muerta con las gentes de la fiesta). Con respecto al término "muerta", no encontramos una carga sombría, sino una imagen de infortunio. Estos elementos fortalecen la contraposición entre la aparente desdicha de la dama y la jerarquía que ostenta el Monseñor.

Debemos resaltar que no estamos ante un desdoblamiento textual en donde la voz del sujeto lírico se dirige a sí mismo ni una continuidad de comunicación con un destinatario definido. Lo que se visualiza con claridad es el proceso semiótico de la interacción de formas idiolectales de una comunicación lingüística. 


\subsection{Secuencialidad del diálogo}

En el proceso semiótico del discurso lírico percibimos el efecto consecutivo de sucesos determinados por la acción y reacción verbal del diálogo. Las reacciones de los personajes se ven determinadas por las conversaciones alternadas, dando información, presentando datos y construyendo la situación comunicativa. Sin la intervención de un narrador, las acotaciones y los signos extraverbales, el diálogo prosigue de manera fluida:

- Monseñor, si semeja una rosa que murmura gentil, misteriosa.

Es tal vez una sombra preclara, Señorón; y ¡qué cara!, ¡qué cara!...

- ¿Es acaso la luna sin vida?

- Una caña del viento florida.

- ¿Y sus ojos son negros y hondos?

- Se diría dos mundos redondos.

No son galos, ni son zahareños, son la noche de todos los sueños.

Con su talle de avispa provoca la elegancia, y su boca jsu boca!...

Cuenta lindo paisajes dormidos, cuenta cielos del alma floridos.

Quiere hablarte con voz de salterio.

La secuencia del argumento expone el intento del emisario de satisfacer las inquietudes del Monseñor con alusiones sobre el rostro y la figura de la misteriosa dama. Estas referencias revelan el desconcierto del emisario tras haber contemplado un semblante 
atractivo. Desde un pensar metafórico, relaciona a la mujer con imágenes de la naturaleza: "si semeja una rosa", una "cańa del viento florida" con "talle de avispa".

Asimismo, el diálogo se potencia con las implicaciones conversacionales de la repetición al declararse en torno al rostro y la boca de la dama. El discurso poético se configura con las iteraciones (“y ¡qué cara!, ¡qué cara!...”, “y su boca ¡su boca!...”) que constituyen un recurso retórico a nivel de sentido para subrayar la belleza de la dama y exponer el desconcierto de quien la ha visto. También existe un pensamiento sinecdóquico: la localización de ciertas partes específicas como la "boca" o los "ojos" nos permite determinar que se trata de una mujer encantadora.

El verso "son la noche de todos los sueños" evidencia la sugerencia del emisario respecto a la carga tétrica de la mirada de la dama, una mirada que traslada al observador a un espacio desolador o a un sueño profundo cubierto de una absoluta oscuridad. Con este enunciado metafórico, se le otorga a la presencia femenina un perfil exuberante y, a la vez, amenazante.

\subsection{Ambigüiedad en el desenlace}

Las alteraciones sucesivas de los personajes nos conllevan hacia el desenlace, dejando establecido la unidad semiótica del discurso dialogado. Las descripciones, elaboradas por el emisario sobre la Muerte, desde un enfoque de lo bello, fomentan el interés del eclesiástico quien desea ver la perfecta belleza de la dama y comprender el motivo de su aparición; sin embargo, de manera sorpresiva, se notifica la peculiar identidad: estamos ante la presencia de la Muerte.

- ¿Qué dirá? ¿Qué anhela?... ¡un misterio!

- Corazón desvelado e inerte,

hoy te cita de amores la Muerte.

El antepenúltimo verso del poema manifiesta un giro repentino en la actitud de "Venturón" ante la impensada "cita": la postura autoritaria se convierte en una temerosa curiosidad por saber la declaración y el deseo de la enigmática damisela. 
Asimismo, se revela el trágico final: la interrupción de la vida, el detenimiento de los latidos del "Corazón desvelado e inerte"; en otros términos, el órgano central del cuerpo, frívolo, carente de ilusión y aliento, será entregado en una reunión "de amores" a la Muerte. Además, el término "hoy" nos coloca en un lapso temporal en el presente en donde la Muerte ha dictaminado el encuentro. De una manera sombría, entonces, se pone fin a la vida del Monseñor, destacando la autoridad de la Muerte.

Semánticamente debemos señalar que el argumento del poema no concluye con un hecho explícito, mas bien sugiere una ambigüedad, específicamente dos posibilidades de desenlace. En primer lugar, si nos amparamos en la linealidad del diálogo entre el emisario y el Monseñor podemos determinar que el emisario es el mensajero de la Muerte con la intención de estimular al Monseñor para que pueda acercarse a las ambiciones de la Muerte. Desde esta perspectiva, el emisario, consciente de la identidad siniestra de la dama, conlleva al Monseñor a su deceso.

En segundo lugar, al encontrarnos con una ausencia de acotaciones directas respecto a quienes emiten cada línea argumentativa, podemos elaborar una resolución distinta. Al concentrarnos en las enunciaciones del emisario, este jamás deja entrever la identidad de la dama, ya que las descripciones revelan su asombro. Así, el momento de la revelación no encaja con el conocimiento previo. De allí que consideremos que la misma Muerte expone su condición tétrica con un ingreso abrupto al espacio en que se encuentran los personajes. Este final, a pesar de no saber certeramente si muere el Monseñor, afianza aún más la tensión dramática: la sentencia de la Muerte indica que puede paralizar la continuidad vital de quien se le plazca.

\section{Conclusiones}

- 1 manejo de los símbolos y el efecto rítmico de los versos demuestran la magistral labor Poética de José María Eguren. Por nuestra parte, el presente estudio ha pretendido evaluar, desde un enfoque semiológico y retórico, un elemento estratégicamente utilizado: el diálogo, estructura con una actividad verbal en donde se alternan dos interlocutores. Partiendo de este enfoque, consideramos que Eguren asume otros mecanismos expresivos como el diálogo con el fin de potenciar las insinuaciones de fatalidad en el poema.

El soporte imaginario extraverbal, el impulso secuencial del diálogo, las alusiones dialógicas en un progresivo desarrollo semántico de la historia, determina que en el discurso lírico de "La cita", sobre la base de una forma versificada, se condensen las sugerencias 
poéticas y situacionales. Las sucesivas intervenciones interactivas, perceptibles de manera fragmentaria, producen una tensión hacia el desenlace.

Comenzando con la participación fugaz del narrador-poeta en la descripción del contexto, "La cita" manifiesta una estructura del diálogo entre el Monseñor y el emisario ante la presencia de la Muerte. Si bien Eguren emplea magistralmente un ritmo en cada estrofa, la incorporación dialógica intensifica y agiliza el texto lírico al punto de intensificar o dramatizar la situación. Solo a partir de este proceso las referencias y las preguntas con sus respectivas respuestas animan a una lectura fluida e inmediata. De esta manera, el asombro de los personajes ante la presencia de una desconocida dama nos traslada a una resolución trágica: pese a que el Monseñor ostenta un poder, no puede escapar de la inevitable reunión con la Muerte.

\section{Referencias}

Arduini, S. (2000). Prolegómenos a una teoría general de las figuras. Murcia, España: Universidad de Murcia.

Basadre, J. (1928). Equivocaciones. Ensayos sobre literatura penúltima. Lima, Perú: La Opinión Nacional.

Bobes, M. del C. (1997). Semiología de la obra dramática. Madrid, España: Arco/ Libros.

Delgado, W. (1984). Historia de la literatura republicana. Nuevo carácter de la literatura en el Perú independiente. Lima, Perú: RIKCHAY.

Eguren, J. M. (2005). Obra poética. Motivos. Prólogo, cronología y bibliografía de Ricardo Silva-Santisteban. Caracas, Venezuela: Biblioteca Ayacucho.

Eguren, J. M. (2015a). Poesías completas (Ed. y N. R. Silva-Santisteban). Lima, Perú: Biblioteca Abraham Valdelomar, Academia Peruana de la Lengua.

Eguren, J. M. (2015b). Prosa completa (Ed. y N. R. Silva-Santisteban). Lima, Perú: Biblioteca Abraham Valdelomar, Academia Peruana de la Lengua.

Elguera, C. (2014). Eguren y el vannitas: notas sobre el poema "La cita". La mula. Recuperado de https://redaccion.lamula.pe/2014/07/29/eguren-y-el-vannitasnotas-sobre-el-poema-la-cita/christianelguera/

Higgins, J. (2006). Historia de la literatura peruana. Lima, Perú: Universidad Ricardo Palma. 


\section{WILLIAMS NICKS VENTURA VÁSQUEZ}

Lino Salvador, L. (2017). La muerte en la mitad de la fiesta de la vida: "La cita" de José María Eguren. Revista americana. Recuperado de http://revistaamericana. com/2017/06/10/la-muerte-en-la-mitad-de-la-fiesta-de-la-vida-la-cita-de-josemaria-eguren/

Ortega, J. (1974). La imaginación crítica. Ensayos sobre la modernidad en el Perú. Lima, Perú: Peisa.

Paraíso, I. (1976). Teoría del ritmo de la prosa. Barcelona, España: Planeta.

Peña Barrenechea, E. (1977). Aspectos de la poesía de Eguren. En Silva-Santisteban, R. (Comp.), José María Eguren. Aproximaciones y perspectivas (111-120). Lima, Perú: Universidad del Pacífico.

Rieco, A. (1998). El "poema escénico": un género híbrido. RILCE. Revista de Filología Hispánica, 14(1), 89-111.

Silva-Santisteban, R. (2017). $\quad$ El universo poético de José María Eguren. Lima, Perú: Cátedra Vallejo. 